\title{
Batch and column test analyses for hardness removal using natural and homoionic clinoptilolite: breakthrough experiments and modeling
}

\author{
Luvina Bibiano-Cruz ${ }^{1} \cdot$ Jaime Garfias $^{1}\left(\mathbb{D} \cdot\right.$ Javier Salas-García $^{1} \cdot{\text { Richard } \text { Martel }^{2} \text { }}^{2}$ \\ Hilario Llanos ${ }^{3}$
}

Received: 18 September 2015/Accepted: 13 March 2016/Published online: 30 March 2016

(c) Springer International Publishing Switzerland 2016

\begin{abstract}
Hard water causes many problems in domestic and industrial usage, which has to be removed using costeffective technologies. To achieve this, the main goal of this study is to assess and optimize the factors controlling water softening applications. The research approach included a combined use of batch and column experiments performed in laboratory conditions through the ion exchange process, evaluating the effectiveness of natural and homoionic clinoptilolite on the removal characteristics of divalent cations. The equilibrium data could be fitted by both the Langmuir and the Freundlich models, even though it was fitted better by the Langmuir model with a maximum adsorption capacity of $10.5 \mathrm{mg} \mathrm{g}^{-1}$ for homoionic clinoptilolite (HC) and $9.68 \mathrm{mg} \mathrm{g}^{-1}$ for the natural clinoptilolite (NC). The adsorption kinetics can be successfully fitted to pseudo-second order kinetic model and the results of the intraparticle diffusion model suggest intraparticle diffusion was not the only rate-controlling step. It was also observed that the statistics indices of agreements from non-linear Thomas model were higher than that linear Thomas model. Nevertheless, the slope of the breakthrough curve for the linearized method decreased with increasing time as compared to non-linear method, thereby resulting in a slightly steeper slope for the nonlinear method and reducing the adsorption capacity. The
\end{abstract}

Jaime Garfias

jgarfiass@gmail.com

1 Faculty of Engineering (CIRA), Autonomous University of the State of Mexico, C.P. 50130 Toluca, Mexico

2 Institut National de la Recherche Scientifique (INRS-ETE), Québec, QC G1K 9A9, Canada

3 Departamento de Geodinámica, Universidad del País Vasco., Vitoria-Gasteiz, Spain study also concludes that the non-linear method is slightly more effective in predicting the performance of the selective removal efficiency of hardness ions. Results illustrate that clinoptilolite may be used as an alternative to more costly materials, due to its low cost and high abundance.

Keywords Hardness - Water softening - Clinoptilolite · Ion exchange $\cdot$ Thomas model

\section{Introduction}

Purification of several contaminants in tap, ground, and river water is needed for the drinking and industrial purposes. Among the contaminants, hard water minerals such as calcium, magnesium, iron, and manganese ions can react with soap anions, decreasing the cleaning efficiency (Park et al. 2007). The minerals also induce scaling problems and serious failures in pipelines of boilers, heat exchangers, and electrical appliances such as washing machines, dishwashers and steam irons (Gabrielli et al. 2006).

To remove the divalent ions, several methods have been widely applied as a means of effective water softening: chemical precipitation, ion exchange process, nanofiltration, reverse osmosis, and electromembrane systems such as electrodialysis, electrodialysis reversal, and electrodeionization reversal. However, in case of the chemical precipitation, the $\mathrm{pH}$ of water increased by adding the alkaline additives and bicarbonates converted into carbonates as the precipitates. Due to the limited solubility of calcium and magnesium salts (carbonates), the hardness of water cannot be removed completely with this method (Yildiz et al. 2003; Williams et al. 2002). In lime softening method, this is limited by the solubility of calcite and removal of carbonate hardness (Stumm and Morgan 1996). 
In membrane systems, monovalent ions and acids released in the regeneration of membrane processes would result in harmful effects on the environment. Finally, high power consumption and expenses are required for operation and maintenance of the equipment (Cuda et al. 2006; Gabrielli et al. 2006; Ghizellaoui et al. 2005; Park et al. 2007). Thus, a cost-effective and low energy consuming treatment process has been forced on water softening process.

Ion exchange involves the replacement of ions adsorbed on the surface of fine grained materials by ions in solution. The most common use of this process is in domestic water softening. Ion exchange processes have been shown to be suitable for removal of hardness ions when this element is in the ionized form (Helferrich 1962; Korngold et al. 2001; Mohan and Pittman 2007). The main advantages with respect to other alternative treatments are: high removal efficiency, low chemical requirements and no modification of drinking water organoleptic properties. In spite of its advanced stage of development, various aspects of ion exchange technology are being studied in many countries to improve its efficiency and economy in its application to hardness removal. Certain characteristics of ion exchange materials and processes limit their applicability and efficiency.

Although ion exchange materials have been used more widely in practice (Rabideau et al. 2005; Han et al. 2007; Chiavola et al. 2012), there still exist some problems: (1) there is a crucial need for the development of a method that is not only cost-effective and economic, but can also be easily implemented. This led to a search for cheaper, easily obtainable materials for the water softening; (2) although the practical applications of hardness removal are generally used in column mode, most research focuses on the batch adsorption mode (Zou et al. 2011), so there is a lack of research on the study of dynamic column methods. Natural clinoptilolite (NC), as aluminosilicate mineral, has characteristics of large surface area, strong capability of ions exchange and adsorption for their particular tetrahedral pore framework. Modeling of the ion exchange process can also help in predicting the performance of the hardness removal processes (Benefield et al. 1982; Chiavola et al. 2012). This can also support in evaluation of the technicaleconomical feasibility of the ion exchange process as compared to alternative systems. Therefore, systematic investigations on the selective removal of divalent ions using ion exchange processes are needed for water softening applications.

In view of the strategic importance of effective removal efficiency of hardness ions, and the growing demands for water of high quality for human consumption, the main goal of this study is to assess and optimize the factors controlling water softening applications, as well as evaluating the effects of modifying the operating conditions. The research approach included a combined use of batch and column experiments performed in laboratory conditions through the ion exchange process, evaluating the effectiveness of natural clinoptilolite (NC) and homoionic clinoptilolite (HC) on the removal characteristics of divalent cations. The obtained breakthrough curves were then modeled and the values of the main constants of the best fitting model determined. This allowed an examination of performance assessment of a clinoptilolite treatment in removing water hardness based on the assumption of competitive cation-exchange as the dominant sorption mechanism.

\section{Materials and methods}

To reduce water hardness, two laboratory procedures were used to determinate the sorption clinoptilolite capacity for hardness ions: batch (isotherms and kinetic models) and column test experiments to obtain breakthrough profiles at various contact times. The collected data were then described using two modeling approaches, based on linear and nonlinear analysis of the Thomas model, respectively. The results of the modeling activity were then compared with the results of column tests performed with synthetic hard water (SHW), obtained with the same ionic concentration as karstic spring water. Error analysis was carried out to test the adequacy and accuracy of the model equations. The features of the different mathematical models used to describe the results of the breakthrough experiments are discussed in the following sections.

\section{Synthetic inorganic surrogate of a natural hard water sample}

To perform experiments relevant to natural water, it can be advantageous to use a medium with the same major ionic composition as the natural water being studied, but without natural constituents, such as trace components, colloids and organic substances. In this study, the freshwater characterization of a karst spring was selected to represent chemical composition of natural hard water (NHW), which was used as reference to prepare a synthetic hard water (SHW) solution in the laboratory to test the affinity between the sorbate and sorbent (Bibiano-Cruz 2009).

The selected natural hard water originates in a karstic formation which is located in the Sierra Madre del Sur province (600 masl), in the State of Guerrero, Mexico, between $100^{\circ} 4^{\prime} 7^{\prime \prime} \mathrm{N}$ and $18^{\circ} 21^{\prime} 57^{\prime \prime} \mathrm{W}$. In this region, the freshwater facies were characterized as $\mathrm{Ca}-\mathrm{HCO}_{3}-\mathrm{Cl}$, enriched in some ions from dissolution of calcite-dolomite and evaporite minerals (Bibiano-Cruz 2009). As a consequence, calcium ions $\left(\mathrm{Ca}^{2+}\right)$ contribute about $90 \%$ of total 
hardness; likewise the calcite oversaturation is due to $\mathrm{CO}_{2}$ outgassing in upwelling spring water.

The SHW solution was prepared according to generic protocol for preparing synthetic freshwaters of desired composition (Smith et al. 2002). This synthetic surrogate emulates the major ion composition and ionic strength of the water characterized (NHW). Most compositions include $\mathrm{Ca}^{2+}, \mathrm{Mg}^{2+}, \mathrm{Na}^{+}$and $\mathrm{K}^{+}$cations and $\mathrm{Cl}^{-}, \mathrm{SO}_{4}{ }^{2-}$, $\mathrm{NO}_{3}^{-}$and $\mathrm{HCO}_{3}^{-}$anions. To avoid oversaturation and precipitation in the SHW solution, the salts were arranged in four groups to prevent incongruent solubility. The salts used in the compatible stock solutions preparation were: Solution A $\left[\mathrm{CaCl}_{2} \cdot 6 \mathrm{H}_{2} \mathrm{O}+\mathrm{Ca}\left(\mathrm{NO}_{3}\right)_{2} \cdot 4 \mathrm{H}_{2} \mathrm{O}\right]$, Solution B $\left[\mathrm{CaCO}_{3}\right]$, Solution $\mathrm{C}\left[\mathrm{KHCO}_{3}+\mathrm{KH}_{2} \mathrm{PO}_{4}+\mathrm{NaHCO}_{3}+\right.$ $\left.\mathrm{Na}_{2} \mathrm{SO}_{4}\right]$ and Solution D $\left[\mathrm{MgSO}_{4} \cdot 7 \mathrm{H}_{2} \mathrm{O}\right]$. To preserve $\mathrm{CaCO}_{3}$ dissolution (Solution $\mathrm{B}$ ), it was necessary to increase the $\mathrm{pCO}_{2}$ during salt dissolution by vigorous bubbling of $\mathrm{CO}_{2}$ gas for $10 \mathrm{~min}$ prior to the addition of the $\mathrm{CaCO}_{3}$ powder, which was continued for $4 \mathrm{~h}$ to prevent residual $\mathrm{CaCO}_{3}$ phase. Thus, the required concentrations of each ion for each salt, as well as the mass of salt required to make up an appropriate volume of each stock solution, were considered to obtain the final volume of the SHW.

Accuracy of ion composition of the NHW was verified by electroneutrality $(\mathrm{EN})$ condition: $\mathrm{EN}(\%)=\left(\Sigma \mathrm{CZ}^{+}\right.$ $\left.-\Sigma \mathrm{AZ}^{-} / \Sigma \mathrm{CZ}^{+}+\Sigma \mathrm{AZ}^{-}\right) \times 100$, where cations and anions are expressed as meq $\mathrm{L}^{-1}$. The final SHW solution was equilibrated by introducing atmospheric $\mathrm{CO}_{2}$ by applying gentle air bubbling during $1 \mathrm{~h}$. As a consequence, the analytic composition of the SHW solution was ranged with a margin of error of $<1 \%$, taking into account $240 \mathrm{mg} \mathrm{L}^{-1}$ of total hardness as $\mathrm{CaCO}_{3}, \mathrm{pH} 6.5 \pm 0.3$ and $100 \mathrm{mg} \mathrm{L}^{-1}$ of $\mathrm{CO}_{2}$. In the SHW solution, the total hardness is a measure of divalent cations and represents the concentration of calcium $\left(\mathrm{Ca}^{2+}\right)$ and magnesium $\left(\mathrm{Mg}^{2+}\right)$ ions, which correspond to the characterized properties of the karstic system. In natural waters other polyvalent ions also contribute to the hardness of water, but they are generally present in much lower concentrations.

\section{Ion exchange adsorbent}

The raw zeolitic material used in this study was the natural clinoptilolite (NC) that was taken from a sedimentary deposit near of the Tehuacan region in the state of Puebla, Mexico. This mineral was initially crushed and sieved to recover the $2.4-4.8 \mathrm{~mm}$ size range to be used throughout the experiments. In this schema, the clinoptilolite was washed with distilled water several times, and dried in an oven set at $100{ }^{\circ} \mathrm{C}$ and stabilized at room temperature to obtain the natural clinoptilolite (NC) form.

To improve the clinoptilolite sorption capacity (BibianoCruz 2009), the natural clinoptilolite (NC) was pretreated with $1 \mathrm{M} \mathrm{NaCl}$ for $24 \mathrm{~h}$ to obtain the homoionic clinoptilolite (HC) sodium form. The samples thus treated were then washed in distilled water to remove any excess of $\mathrm{NaCl}$ present on the surface, and dried in an oven set at $100{ }^{\circ} \mathrm{C}$ and stabilized at room temperature for $24 \mathrm{~h}$. The pretreatment of clinoptilolite was conducted based on the findings of previous studies that alkali and alkaline earth metals are cheap, commonly available and are the most effective exchangeable ions for hardness removal (Gorimbo et al. 2014).

\section{Determination of exchange capacity}

\section{Batch contact time experiments}

Sorption mechanisms depend on the sorbate-sorbent interaction and the system conditions, therefore the sorption capacity and required contact time were two of the important parameters to determine. The bottle point isotherm technique (Rivas et al. 2006) was employed to determine the equilibrium capacity of the $\mathrm{NC}$ and $\mathrm{HC}$ for hardness removal in the SHW solution. Batch sorption experiments were conducted to determine the relationship between adsorbent and adsorbate by varying the amounts of adsorbate, both at equilibrium and as a function of time.

The influence of adsorbent mass on the rate of hardness sorption was determined by carrying out contact time experiments using batch agitated reactor. Experimental studies were conducted at room temperature $\left(20 \pm 1{ }^{\circ} \mathrm{C}\right)$ by varying the adsorbent mass at the initially defined $\mathrm{pH}$ of the SHW solution. Accordingly, experiments were carried out in $250 \mathrm{ml}$ flasks sealed by Parafilm $\odot$ with varying adsorbent mass from $0.5,1,3,5,10,20$ and $30 \mathrm{~g}$ mixed with $200 \mathrm{ml}$ of the SHW solution. In this context, the samples were stirred continuously at $200 \mathrm{rpm}$ (Big Bill Digital Thermolyne shaker). Upon equilibration time $(24 \mathrm{~h})$, the total hardness in the liquid phase was measured and the absorbance accumulation on the adsorbent was calculated via a mass balance.

To obtain the sorption capacity (Benguella and Benaissa 2002), the amount of hardness of the SHW adsorbed $\left(q_{\mathrm{t}}\right)$ per unit mass of clinoptilolite was calculated with the following equation:

$q_{\mathrm{t}}=\frac{\left(C_{0}-C_{\mathrm{t}}\right) \cdot V}{W}$,

where $q_{\mathrm{t}}$ is the amount of hardness removed from the SHW solution $\left(\mathrm{mg} \mathrm{g}^{-1}\right)$ at time $\mathrm{t} ; C_{0}$ is the initial hardness concentration of adsorbate $\left(\mathrm{mg} \mathrm{L}^{-1}\right) ; C_{\mathrm{t}}$ is the equilibrium concentration of hardness left in the solution after the experiment $\left(\mathrm{mg} \mathrm{L}^{-1}\right) ; V$ is the solution volume (L), and $W$ is the weight of clinoptilolite $(\mathrm{g})$. 
There are three isotherm models that have been widely used to represent the response curves: namely linear, Langmuir, and Freundlich models. The decision to select the best model is based on the pattern of the sorption curves. Adsorption isotherms describe the relationship between the amount of adsorbed ion on adsorbent and the final ion concentration in the solution. In this study, the Langmuir (LG) (Eq. 2) and Freundlich (FR) (Eq. 3) isotherm models were tested to adequately correlate the experimental data to find the best fit of the experimental data. The parameters for FR and LG isotherms are very useful for predicting adsorption capacities and also for incorporating into mass transfer relationships in the design of contacting equipment. The non-linear equation of Langmuir isotherm model is expressed as follows.

$q_{\mathrm{e}}=\frac{q_{\mathrm{m}} b C_{\mathrm{e}}}{1+b C_{\mathrm{e}}}$,

where $C_{\mathrm{e}}\left(\mathrm{mg} \mathrm{L}^{-1}\right)$ and $q_{\mathrm{e}}\left(\mathrm{mg} \mathrm{g}^{-1}\right)$ are the concentration of hardness ions in the liquid and solid phases, $q_{\mathrm{m}}\left(\mathrm{mg} \mathrm{g}^{-1}\right)$ is the amount of solute adsorbed per unit weight adsorbent in forming a complete monolayer on the surface, $b$ $\left(\mathrm{L} \mathrm{mg}^{-1}\right)$ is the constant related to the energy or net enthalpy of adsorption intensity. The Freundlich isotherm model is an empirical expression used in heterogeneous systems and it is expressed as follows:

$q_{\mathrm{e}}=K_{\mathrm{F}} C_{\mathrm{e}}^{1 / n}$,

where $C_{\mathrm{e}}\left(\mathrm{mg} \mathrm{L}^{-1}\right)$ and $q_{\mathrm{e}}\left(\mathrm{mg} \mathrm{g}^{-1}\right)$ are the concentration of hardness ions in the liquid and solid phases, $K_{\mathrm{F}}\left(\mathrm{mg}^{1-n} \mathrm{~L}^{n-}\right.$ $\mathrm{g}^{-1}$ ) is the adsorption coefficient and represents the adhesion ability of the adsorbate onto the adsorbent (relative adsorption capacity of the adsorbent), $n$ (dimensionless) is the adsorption equilibrium constant whose reciprocal is indicative of adsorption intensity, respectively.

\section{Kinetics of adsorption}

To study the equilibrium time and adsorption rate, a series of experiments were conducted to examine the adsorption capacity of adsorbent mass using a SHW solution at constant temperature $\left(24 \pm 1{ }^{\circ} \mathrm{C}\right)$. For the entire experiments, $1 \mathrm{~g}$ of a constant adsorbent mass was added to $100 \mathrm{ml}$ of the SHW solution in $250 \mathrm{ml}$ flasks and placed on a shaker at $200 \mathrm{rpm}$. The initial total hardness concentration of SHW was $240 \mathrm{mg} \mathrm{L}^{-1}$ with a value of $\mathrm{pH} \sim 6.5 \pm 0.3$. A blank containing $100 \mathrm{ml}$ of SHW solution without any adsorbent was shaken simultaneously to determine any adsorption process onto the walls of the flasks. The equilibrium for the investigated systems was established for 5 , 15, 30 and $60 \mathrm{~min}$ and then 3, 6, 12, 18 and $24 \mathrm{~h}$. After samples collection, the total hardness concentrations were determined with a FF-2 HACH test kit by titration method. The experiment was performed in duplicate at room temperature $\left(20^{\circ} \mathrm{C}\right)$.

The kinetic parameter study, which is helpful for the prediction of adsorption rate, was performed based on pseudo-first order, pseudo-second order and intraparticle diffusion models, respectively. Lagergren first order model (Eq. 4) is expressed by the following equation:

$q_{\mathrm{t}}=q_{\mathrm{e}}\left(1-e^{-\mathrm{k}_{1} t}\right)$,

where $k_{1}=$ Lagergren rate constant for adsorption $\left(\mathrm{h}^{-1}\right)$, $q_{\mathrm{e}}=$ amount of ion adsorbed at equilibrium $\left(\mathrm{mg} \mathrm{g}^{-1}\right)$ and $q_{\mathrm{t}}=$ amount of ion adsorbed at any given time $t\left(\mathrm{mg} \mathrm{g}^{-1}\right)$. According to Ho et al. (2000), the pseudo-second order is described by the following equation:

$q_{\mathrm{t}}=\frac{k_{2} q_{\mathrm{e}}^{2} t}{\left(1+k_{2} q_{\mathrm{e}} t\right)}$,

where $k_{2}=$ pseudo-second order rate constant for adsorption $\left(\mathrm{g} \mathrm{mg}^{-1} \mathrm{~h}^{-1}\right), q_{\mathrm{e}}=$ amount of ion adsorbed at equilibrium $\left(\mathrm{mg} \mathrm{g}^{-1}\right)$ and $q_{\mathrm{t}}=$ amount of ion adsorbed at any given time $t\left(\mathrm{mg} \mathrm{g}^{-1}\right)$. Data from batch experiments were fitted to both models by nonlinear regression analysis using software package SPSS v.13 for Windows (SPSS Inc., Chicago, USA).

The diffusivity of the solute molecules has an important effect on the total rate of an adsorption process. Since the pseudo-first and the pseudo-second order kinetic models cannot identify the influence of diffusion on sorption, the Weber and Morris equation was used for calculation of the rate constants of intraparticle diffusion (Weber and Morris 1964). The intraparticle diffusion model presumes that film diffusion or boundary layer diffusion is negligible, and that intraparticle diffusion is the only rate-controlling step. The rate of intraparticle diffusion can be calculated according to the following equation:

$q_{\mathrm{t}}=C_{\mathrm{d}}+k_{\mathrm{d}} t^{1 / 2}$,

where $k_{\mathrm{d}}$ is the intraparticle diffusion rate constant (mmol g ${ }^{-1} \min ^{-0.5}$ ), and $C_{\mathrm{d}}$ is the intercept which is proportional to the boundary layer thickness $\left(\mathrm{mmol} \mathrm{g}^{-1}\right)$. The rate constant of intraparticle transport, $k_{\mathrm{d}}$, is estimated from the slope of the linear portion of the plot of amount sorbed against square root of time. In the case of a linear plot of $q_{\mathrm{t}}$ vs $t^{0.5}$, and if the line passes through the origin, intraparticle diffusion is the only rate-controlling step. If not, some other mechanisms are also involved.

\section{Column sorption studies}

Although batch laboratory adsorption studies provide useful data and parameters on the application of adsorbents for 
hardness removal, the data obtained from batch adsorptive system are not applicable to continuous adsorptive system, thus continuous sorption studies are needed. Fixed-bed column experiments were also necessary to provide practical operational information with respect to the adsorption of constituents with the use of clinoptilolite as inorganic ion exchangers.

Column studies were conducted using a Plexiglass $(\odot$ column with an inner diameter of $5 \mathrm{~cm}$ and a length of $50 \mathrm{~cm}$. Schematic details of the column test apparatus and experimental column set-up is illustrated in Fig. 1, including external components to estimate water softening process. The column was completely filled for each test with $1122.5 \mathrm{~g}$ of both $\mathrm{NC}$ and $\mathrm{HC}$ forms. The influent concentration and flow rate of the SHW solution were keep constants at $240 \mathrm{mg} \mathrm{L}^{-1}$ and $14 \mathrm{ml} \mathrm{min}^{-1}$, respectively. Duplicate samples were collected at regular intervals of time for determination of total hardness analysis with a FF$2 \mathrm{HACH}$ test kit by titration method. Column studies were terminated when the column reached exhaustion. The breakthrough curve for the column was determined by plotting the ratio of the $C_{\mathrm{t}} / C_{0}\left(C_{\mathrm{t}}\right.$ and $C_{0}$ are the hardness concentration of effluent and influent, respectively) against the time.

\section{Experimental parameters of breakthrough curves}

There are several experimental parameters, which were calculated for the column hardness sorption process
Fig. 1 Schematic details of the column test apparatus and experimental column set-up, including external components to estimate water softening process

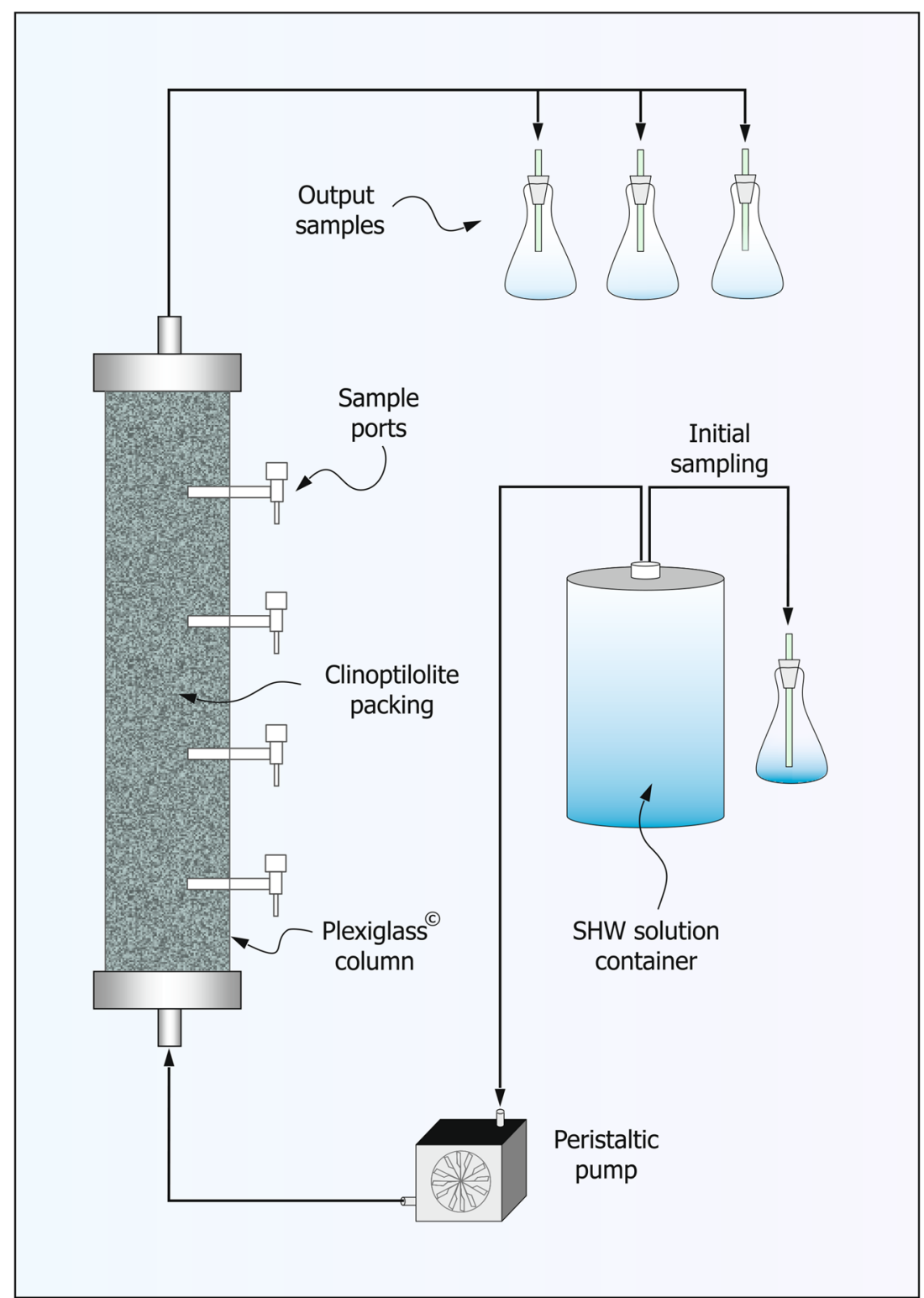


(Singh et al. 2012). Total hardness sorption by the column at saturation, $q_{\mathrm{tot}}(\mathrm{mg})$, was calculated as follows:

$q_{\mathrm{tot}}=\frac{\left(C_{0}-C_{\mathrm{sat}}\right) \cdot t_{s} \cdot Q_{\mathrm{v}}}{1000}=\left(C_{0}-C_{\mathrm{sat}}\right) \cdot V_{s}$,

where $t_{s}$, is the saturation time of the column ( $\left.\mathrm{min}\right), Q_{\mathrm{v}}$ is the flow rate $\left(\mathrm{ml} \mathrm{min}^{-1}\right)$ and $V_{s}$ is the total volume $(L)$ of effluent stored till saturation, respectively. $C_{0}$ is the total hardness concentration of influent $\left(\mathrm{mg} \mathrm{L}^{-1}\right)$ and $C_{\text {sat }}$ is the effluent hardness concentration $\left(\mathrm{mg} \mathrm{L}^{-1}\right)$ at $V_{\mathrm{s}}$, respectively.

Total hardness sorption at saturation by per unit dry weight of the clinoptilolite in the column, $q_{\mathrm{s}}\left(\mathrm{mg} \mathrm{g}^{-1}\right)$, was calculated using Eq. 8:

$q_{\mathrm{s}}=\frac{q_{\mathrm{tot}}}{M}$,

where $M$ is the total dry weight $(\mathrm{g})$ of clinoptilolite packed in the column. Percent removal of hardness $(\% H R)$ at saturation of the column was calculated according to Eq. 9:

$\% H R=\frac{q_{\text {tot }}}{H_{\text {tot }}} \cdot 100$,

where $H_{\text {tot }}$ is the total amount of hardness (mg) supplied to the column till saturation. $H_{\text {tot }}$ was calculated by Eq. 10 :

$H_{\mathrm{tot}}=\frac{C_{0} \cdot Q_{\mathrm{v}} \cdot t_{s}}{1000}$.

The total hardness sorption at breakthrough, $q_{\mathrm{tb}}(\mathrm{mg})$, was calculated by the following equation:

$q_{\mathrm{tb}}=\frac{\left(C_{0}-C_{\mathrm{tb}}\right) \cdot t_{b} \cdot Q_{\mathrm{v}}}{1000}=\left(C_{0}-C_{\mathrm{tb}}\right) \cdot V_{\mathrm{b}}$,

where $V_{\mathrm{b}}$ is the total volume $(\mathrm{L})$ of effluent collected till breakthrough and $C_{\mathrm{tb}}$ is hardness concentration $\left(\mathrm{mg} \mathrm{L}^{-1}\right)$ of $V_{\mathrm{b}}$ at time $t_{\mathrm{b}}$. In the present study, breakthrough of hardness sorption was assumed to have reached when effluent metal concentration reached $100 \mathrm{mg} \mathrm{L}^{-1}$ (Bibiano-Cruz 2009). The total hardness sorption at breakthrough by per unit dry weight of clinoptilolite granules packed in column, $q_{\mathrm{b}}\left(\mathrm{mg} \mathrm{g}^{-1}\right)$, was calculated by dividing $q_{\mathrm{tb}}$ by $M$.

\section{Theoretical modeling of breakthrough curves}

Various mathematical models can be used to describe fixed-bed adsorption. Among these the Thomas model (1948) is often adopted to predict the adsorptive curve of breakthrough in fixed mode (Han et al. 2007). Thomas solution is simple to use and is one of the most general and widely used methods in column performance theory. Thus, the breakthrough data obtained from the column studies were examined using this kinetic model. The expression of the Thomas model for an adsorption column is as follows (Reynolds and Richards 1996; Fu and Viraraghavan 2003):

$\frac{C_{\mathrm{t}}}{C_{0}}=\frac{1}{1+\exp \left[\frac{k_{\mathrm{T}}}{Q_{\mathrm{v}}}\left(q_{0} M-C_{0} V\right)\right]}$,

where $k_{\mathrm{T}}$ is the Thomas rate constant $\left(\mathrm{ml} \mathrm{min}^{-1} \mathrm{mg}^{-1}\right) ; q_{0}$ is the equilibrium hardness uptake per $g$ of adsorbent $\left(\mathrm{mg} \mathrm{g}^{-1}\right) ; M$ is the mass of clinoptilolite in the column $(\mathrm{g})$; $C_{0}$ is the influent hardness concentration $\left(\mathrm{mg} \mathrm{L}^{-1}\right) ; C_{\mathrm{t}}$ is the effluent hardness concentration $\left(\mathrm{mg} \mathrm{L}^{-1}\right)$ at time $t ; Q_{\mathrm{v}}$ is the flow rate $\left(\mathrm{ml} \mathrm{min}^{-1}\right)$. The value of $C_{\mathrm{t}} / C_{0}$ is the ratio of effluent and influent hardness concentrations. The value of $t$ is the flow time (min), $t=V / Q_{\mathrm{v}}, V$ is the throughput volume of the SHW (L) at time $t$. The linearized form of the Thomas model is as follows (Han et al. 2007):

$\ln \left(\frac{C_{0}}{C_{\mathrm{t}}}-1\right)=\frac{k_{\mathrm{T}} q_{0} m}{V}-k_{\mathrm{T}} C_{0} t$.

The values of $k_{\mathrm{T}}$ and $q_{0}$ can be determined from a plot $\mathrm{ln}$ $\left[\left(C_{0} / C_{\mathrm{t}}\right)-1\right]$ against $t$ at a given flow rate using linear least square regressive analysis or from a plot of $C_{\mathrm{t}} / C_{0}$ against $t$ using non-linear regression analysis as the values of $C_{\mathrm{t}} / C_{0}$ are within $0.05-0.95$. For the non-linear form of the Thomas model, Eq. 12 can be converted to the simple format as follows:

$\frac{C_{\mathrm{t}}}{C_{0}} \approx \frac{1}{1+\exp (b-a V)}$,

where:

$a=\frac{k_{\mathrm{T}} C_{0}}{Q_{\mathrm{v}}}$,

$b=\frac{k_{\mathrm{T}} q_{0} M}{Q_{\mathrm{v}}}$.

Therefore, if $Q_{\mathrm{v}}, M$ y $C_{0}$ are constants, $C_{\mathrm{t}} / C_{0}$ is a function of $V$. Once $a$ and $b$ are determinate, $k_{\mathrm{T}}$ and $q_{0}$ can be calculated by the following equation derived from Eqs. 17 and 18:

$k_{\mathrm{T}}=\frac{a Q_{\mathrm{v}}}{C_{0}}$,

$q_{0}=\frac{b Q_{\mathrm{v}}}{k_{\mathrm{T}} M}$.

\section{Error analysis}

In recognition of the nature of the dynamic behavior of the fixed-bed sorption column, it has been necessary to introduce several criteria for the quantification of different aspects of the Thomas model performance. The statistical 
criteria used in the quantitative evaluation indicate an estimation of error between experimental and theoretical values of $C_{\mathrm{t}} / C_{0}$ used for plotting breakthrough curves. Hence, in this study the Nash-Sutcliffe coefficient (NS), the root mean square error (RMSE), the mean absolute error $(M A E)$, and the residual bias $(B I A S)$ were used to confirm the best fit to remove hardness from water (Han et al. 2007). The lower limit for $M A E$ and $R M S E$ is zero. The maximum value for $N S$ is one. Both $N S$ and BIAS can be negative. A large $B I A S$ value represents the worst case performance of the model, while a large RMSE value shows how much the simulations overestimate or underestimate the measurements. The RMSE is more appropriate to represent model performance than the $M A E$ when the error distribution is expected to be Gaussian. The NS coefficient ranges from minus infinity to 1 with higher values indicating better agreement.

\section{Results and discussion}

Laboratory batch studies are useful in obtaining and providing fundamental equilibrium adsorption and kinetic data for potential adsorbents. The importance of obtaining isotherms and kinetics curves lies in developing a model which accurately represents the results obtained and could be used for design purposes. Moreover, the models applied to describe the breakthrough behavior have a key role in the scale-up procedure from laboratory experiments through pilot plant to industrial scale.

\section{Sorption isotherms}

Adsorption isotherm is the most important information to indicate how adsorbate molecules distribute between the liquid phase and solid phase when adsorption process reaches an equilibrium state. In this study, Langmuir and Freundlich equations (Eqs. 2, 3) were used for predicting sorption capacities (i.e., sorption isotherms) and also additional information derived from the estimated parameters (i.e. sorption nature, surface heterogeneity, etc.). In this context, the estimated values of the parameters (Langmuir values $q_{\mathrm{m}}$ and $b$ and Freundlich values $K_{\mathrm{F}}$ and $n$ ) derived from these isotherms were calculated and are displayed in Table 1, together with the corresponding correlation coefficient.

As it is indicated in Fig. 2a, b, sorption isotherms for removal hardness ions adsorbed onto $\mathrm{NC}$ and $\mathrm{HC}$ exhibited differences in shape and in the amount retained. However, both saturation capacities of adsorbents may seem low because the SHW solution is unsaturated of hardness ions. As pointed out by Ho et al. (2000), sorption processes may include ion exchange, chelation, physical and chemical sorption, as well as heterogeneity of the clinoptilolite surface and the wide range of pore sizes and surface properties make an analysis of the observed behavior complex.

Taking into consideration the values of the correlation coefficient $(r)$, it can be observed that their values are very close for both equations. In spite of all this, Langmuir equation gives better correlation ( 0.99 for $\mathrm{NC}$ and $\mathrm{HC}$ ) between the theoretical and experimental data than Freundlich Eq. (0.97 for NC and 0.96 for HC) (Table 1). A better fit of the experimental data for Langmuir equation explain the heterogeneity of the clinoptilolite structure, so the strength of the bond created between the surface and the preferential removal of the hardness ions are not the same for all sites. As a result, the simplifying of assumptions is a necessity in the analysis, accepting the limitations resulting from it.

As presented in Table 1, the Langmuir adsorption capacities $\left(q_{\mathrm{m}}\right)$ on $\mathrm{NC}$ and $\mathrm{HC}$ forms were estimated to be $9.68 \mathrm{mg} \mathrm{g}^{-1}$ (NC) and $10.50 \mathrm{mg} \mathrm{g}^{-1}$ (HC), respectively. The $q_{\mathrm{m}}$ values in the Langmuir isotherm indicate the monolayer adsorption capacity of the low cost absorbent (clinoptilolite) for removal water hardness present in the SHW solution. According to Langmuir equation (Eq. 2), the results exhibited that the hardness ions shows a stronger affinity for $\mathrm{HC}$ than for the NC. On the basis of this explanation, suggested that the preferential removal of the hardness ions occurs on a homogeneous surface by monolayer adsorption. Similar observations have been reported by Cinar and Beler-Baykal (2005) for the removal of water harness ions by natural zeolites through ion exchange treatment.

The Freundlich isotherm (Eq. 3) is an empirical model and it is widely recommended due to its accuracy. This fairly satisfactory empirical isotherm can be used for non ideal sorption that involves heterogeneous sorption. It gives more accurate results than the Langmuir isotherm for a wide variety of heterogeneous adsorption system. This isotherm was selected in the analysis, which would enable better fitting of the experimental adsorption equilibrium data. The magnitude of the exponent $n$ in Freundlich isotherm gives an indication of the favorable nature of the sorption hardness system. The $\mathrm{n}$ values (Table 1) obtained were 1.98 for $\mathrm{NC}$ and 2.65 for $\mathrm{HC}$, which represents a range of beneficial adsorption between $1<n<10$ for several investigated systems (Meshko et al. 2001). Values of $n$ in the range of 1.1-1.4 reflects the linear trend of the isotherm (Rivas et al. 2006). In the present study, since $n$ lies between 1 and 10 it indicates the physical adsorption of hardness ions onto absorbent media. Nearly similar results have been reported in the literature (Mittal et al. 2007; Liu et al. 2010) for Langmuir and Freundlich models. 
Table 1 Parameters of the equilibrium isotherms to determine clinoptilolite exchange capacity and kinetic parameters of the first order and second order adsorption, and intraparticle diffusion rate constants

\begin{tabular}{|c|c|c|c|}
\hline Model & Parameter & Natural clinoptilolite & Homoionic clinoptilolite \\
\hline \multirow{3}{*}{ Langmuir } & $q_{\mathrm{m}}\left(\mathrm{mg} \mathrm{g}^{-1}\right)$ & 9.68 & 10.50 \\
\hline & $b\left(\mathrm{~L} \mathrm{mg}^{-1}\right)$ & $2.02 \times 10^{-2}$ & $3.56 \times 10^{-2}$ \\
\hline & $r$ & 0.99 & 0.99 \\
\hline \multirow{3}{*}{ Freundlich } & $K_{\mathrm{F}}\left(\mathrm{mg}^{1-\mathrm{n}} \mathrm{L}^{\mathrm{n}} \mathrm{g}^{-1}\right)$ & $7 \times 10^{-4}$ & $1.5 \times 10^{-3}$ \\
\hline & $n$ & 1.98 & 2.65 \\
\hline & $r$ & 0.97 & 0.96 \\
\hline \multirow{3}{*}{ Lagergren first order model } & $k_{1}\left(\mathrm{~h}^{-1}\right)$ & $2.78 \times 10^{-3}$ & $4.69 \times 10^{-3}$ \\
\hline & $q_{\mathrm{e}}\left(\mathrm{mg} \mathrm{g}^{-1}\right)$ & 10.22 & 11.58 \\
\hline & $r$ & 0.994 & 0.985 \\
\hline \multirow{3}{*}{ Pseudo-second order model } & $k_{2}\left(\mathrm{~g} \mathrm{mg}^{-1} \mathrm{~h}^{-1}\right)$ & $2.13 \times 10^{-4}$ & $4.20 \times 10^{-4}$ \\
\hline & $q_{e}\left(\mathrm{mg} \mathrm{g}^{-1}\right)$ & 12.90 & 13.45 \\
\hline & $r$ & 0.996 & 0.992 \\
\hline \multirow{3}{*}{ Intraparticle } & $k_{\mathrm{d}}\left(\mathrm{mmol} \mathrm{g} \mathrm{g}^{-1} \min ^{-0.5}\right)$ & 0.260 & 0.231 \\
\hline & $C_{\mathrm{d}}\left(\mathrm{mmol} \mathrm{g}^{-1}\right)$ & 0.982 & 3.899 \\
\hline & $r$ & 0.93 & 0.95 \\
\hline
\end{tabular}

\section{Batch kinetics studies}

Sorption kinetics is useful for selecting optimum operational conditions of water treatment facilities for full-scale processes. Figure 3 depicts the effect of contact time for the hardness adsorption $\left(q_{\mathrm{t}}\right)$ on $\mathrm{NC}$ and $\mathrm{HC}$ in function of the contact time. In the adsoption test, the rate of hardness removal was relatively fast at the beginning due to the greater availability of the clinoptilolite surface area at the start of the experiment. For both $\mathrm{NC}$ and $\mathrm{HC}$ form the hardness sorption shows a quickly tendency to reach equilibrium starting at $6 \mathrm{~h}$ with a maximum percent removal attained after about 12 h. It is evident from Fig. 3 that hardness sorption occurred in two steps, that is, $\approx 62 \%$ of sorption occurred within $6 \mathrm{~h}$ followed by a very slow sorption between 12 and $24 \mathrm{~h}$, that according to Dişli (2010) can be attributed to diffusion process. After $18 \mathrm{~h}$ the removal percentage remained relatively constant reaching $100 \%$ at $24 \mathrm{~h}$.

Lagergren and Ho's models described the sorption kinetics with similar $r$ values: (0.994) for NC and slightly lower value (0.985) for HC (Fig. 3). Nevertheless, both models are capable of modeling the adsorption regardless of the type and amount of clinoptilolite used, describing adequately the kinetic data. The values of rate parameters and correlation coefficient $(r)$ have been obtained and listed in Table 1. It is observed that the pseudo-second order model yields a somewhat better fit than the Lagergren model by comparing the results of correlation coefficients. This suggests that this sorption system is not a first order reaction and that the pseudo-second order model, based on the assumption that the rate-limiting step may be chemical sorption or chemisorption involving valency forces through sharing or exchange of electrons between sorbent and sorbate, provides the best correlation of the data (Ho and McKay 1999). As a consequence, the kinetics of the process indicates a decrease in the rate of sorption in the range $6-18 \mathrm{~h}$ to attain equilibrium conditions. This conclusion is consistent with those studies demonstrating that the pseudo-second-order kinetic model is reasonably good fit of data over the entire adsorption process (Chen et al. 2010).

As discussed above, the preferential removal of the water hardness ions on $\mathrm{HC}$ than on $\mathrm{NC}$ form, suggest that this removal capability is favored by the sodium homoionization which gives preference to different mechanisms involved in the adsorption process. Hence, for investigated hardness ions sorption by $\mathrm{NC}$ and $\mathrm{HC}$, the plots $q_{\mathrm{t}}$ versus $t^{1 / 2}$ did not pass through the origin (Fig. 4) suggesting that even though the adsorption process involved intraparticle diffusion, it was not the only ratecontrolling step. In this regard, this can be attributed to the concentration driving force, bulk concentration minus surface liquid concentration, which decreases rapidly and so its influence is usually limited to the early stages of adsorption. The positive value of intercept $C_{\mathrm{d}}$ is indicative of some degree of boundary layer control (Özcan and Özcan 2004). In this study, as can be seen from Fig. 4 and Table 1, it appears that the thickness of the boundary layer for homoionic clinoptilolite is greater than for natural clinoptilolite.

The multilinear shape of $q_{\mathrm{t}}-t^{1 / 2}$ relationships indicates that more than one process affects adsorption of divalent ions. As can be seen from Fig. 4, plot $q_{\mathrm{t}}$ versus $t^{1 / 2}$ for hardness ions has first sharper portion, which can be considered as an external surface adsorption or faster adsorption stage, followed by gradual adsorption where intraparticle diffusion is rate controlled. After that, in the 
Fig. 2 Langmuir and Freundlich isotherms in batch experiments for: a natural clinoptilolite (NC) and b homoionic clinoptilolite (HC)
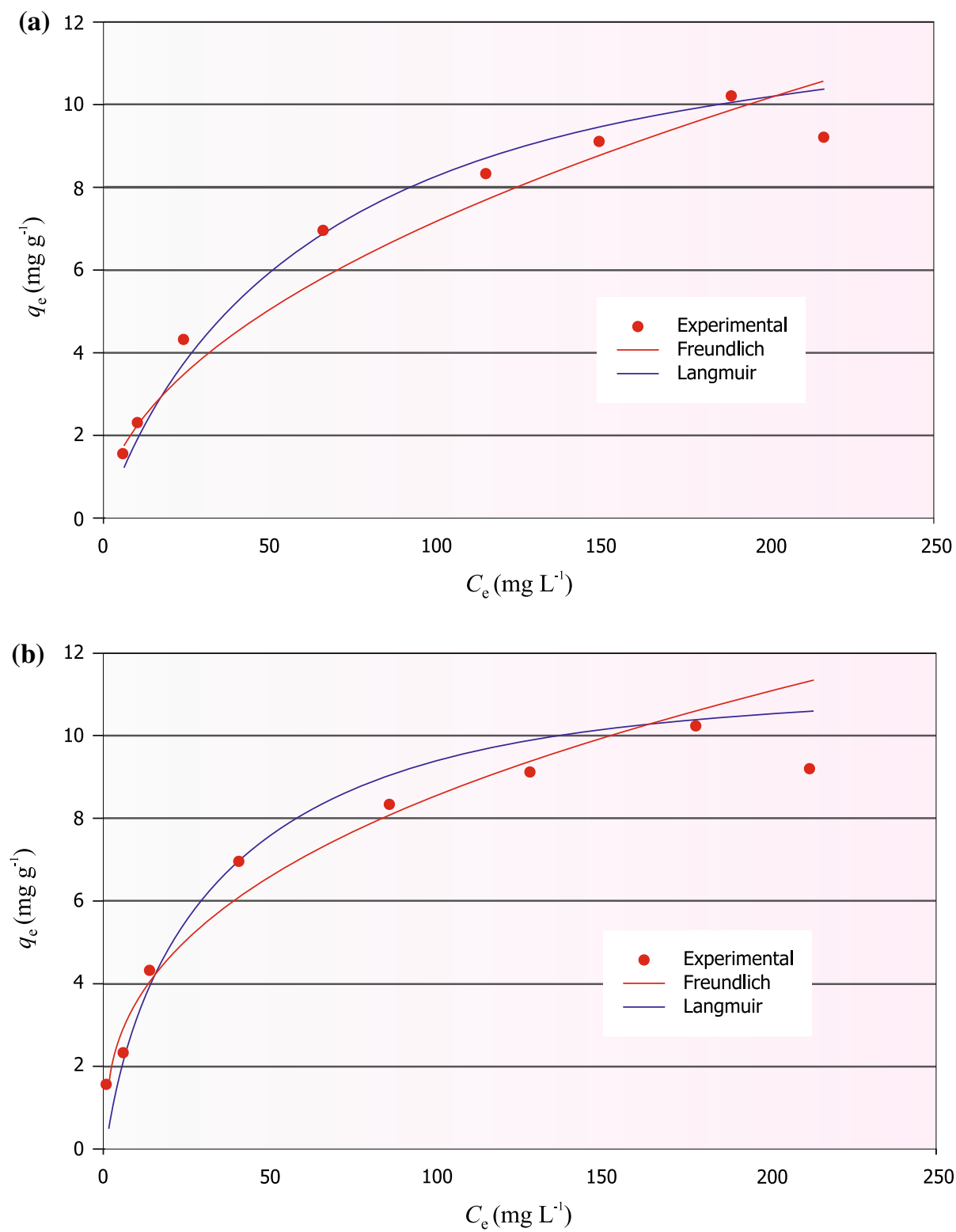

final equilibrium stage the intraparticle diffusion starts to slow down due to the low adsorbate concentration in solution. Kumar et al. (2009) observed a similar behavior for $\mathrm{Cr}$ (III) removal using an amine-based polymer, anilineformaldehyde condensate (AFC) coated on silica gel.

\section{Column sorption studies}

\section{Breakthrough curves for hardness sorption}

Breakthrough in column tests can be defined as the amount of influent solution passing through the bed before a maximum effluent concentration is reached (Eckenfelder 2000; Zhou et al. 2004). The ratio $C$ (total hardness concentration in the SHW effluent) $/ C_{0}$ (hardness concentration of the SHW influent) was plotted against the volume of the SHW solution passed, and the top $x$ axis shows the time taken for passing the SHW solution through the column.

Taking into consideration the above results, the breakthrough volume and the time to sorption of hardness ions on clinoptilolite is gradual, thus resulting in relatively slow attainment of breakthrough. In this research, breakthrough and exhaustion are defined as the phenomena when the ratios of effluent-to-influent concentration are 5 and $95 \%$, respectively (Zhou et al. 2004). Thus, the breakthrough point $\left(C / C_{0} \leq 5 \%\right)$ for the $\mathrm{NC}$ was $10.42 \mathrm{~L}$ (12.5 min) and $19.59 \mathrm{~L}(23.5 \mathrm{~min})$ for $\mathrm{HC}$, as well as the exhaustion point $\left(C / C_{0} \leq 95 \%\right)$ for the $\mathrm{NC}$ was $140.52 \mathrm{~L}(168.5 \mathrm{~min})$ and $165.97 \mathrm{~L}(199 \mathrm{~min})$ for $\mathrm{HC}$. 
Fig. 3 Lagergren's first order and Hós pseudo-second order model plots for the batch kinetics of hardness adsorption on: a natural clinoptilolite (NC) and $\mathbf{b}$ homoionic clinoptilolite (HC)
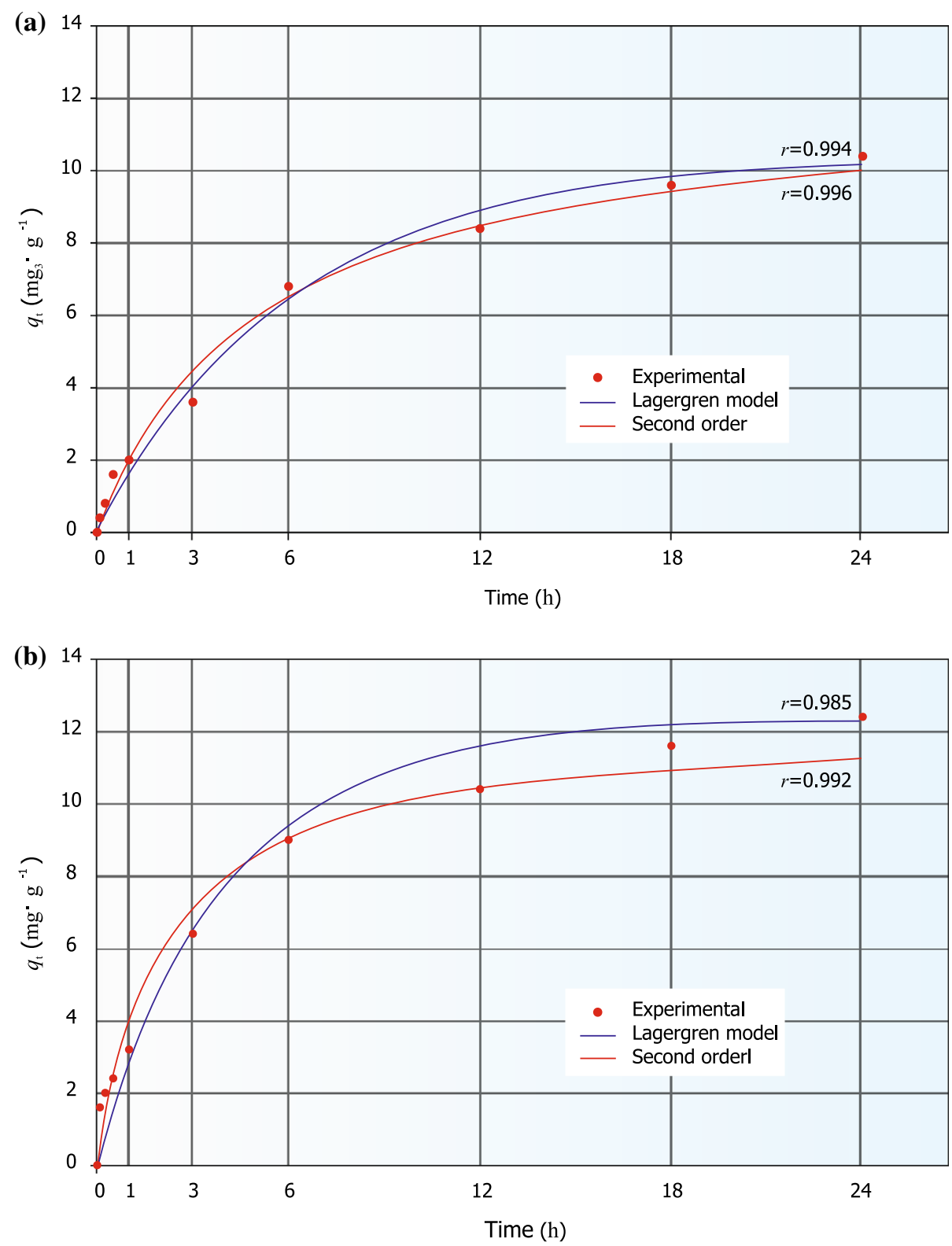

A summary of the experimental parameters of the ion exchange column packed with $\mathrm{NC}$ and $\mathrm{HC}$ for water softening are presented in Table 2. In this context, for an initial water hardness concentration $\left(C_{0}\right)$ of $240 \mathrm{mg} \mathrm{L}$, a clinoptilolite dry weight mass (M) of $1122.5 \mathrm{~g}$ and a flow rate of $14.5 \mathrm{ml} \mathrm{min}^{-1}$, the breakthrough time $\left(t_{\mathrm{b}}\right)$ and the breaktrough volume $\left(V_{\mathrm{b}}\right)$ was higher for $\mathrm{HC}$ than for $\mathrm{NC}$ form $(\sim 80 \%, 22$ vs. $12 \mathrm{~min}$ and 18 vs. $10 \mathrm{~L})$. However, differences between values of the saturation time $\left(t_{\mathrm{s}}\right)$ and the saturation volume $\left(V_{\mathrm{s}}\right)$ for the $\mathrm{HC}$ and the $\mathrm{NC}$ form was only $\sim 5 \%$ (199 vs. $188 \mathrm{~min}$ and 170 vs. $160 \mathrm{~L}$ ). Thus, the sorption at breakthrough $\left(q_{\mathrm{tb}}\right)$ and the sorption at saturation $\left(q_{\mathrm{e}}\right)$ was $\sim 30 \%$ higher for the $\mathrm{HC}$ in comparison with $\mathrm{NC}$ ( 4.87 vs. $3.76 \mathrm{mg} \mathrm{g}^{-1}$ and 15.4 vs. $12 \mathrm{mg} \mathrm{g}^{-1}$ ). Consequently, these values result in a capacity removal at saturation (HR) for the $\mathrm{NC}$ of 33.1 and $42.5 \%$ for $\mathrm{HC}$ form (Table 2).

Considering the $\mathrm{NC}$ form, the sorption of hardness ions by the clinoptilolite was faster than that for $\mathrm{HC}$, thus resulting in quick attainment of breakthrough and saturation. The hardness sorption at breakthrough and at saturation was greater for the $\mathrm{HC}$ because its homoionic form provided better driving force in the ion exchange softening process during continuous column run. 
Fig. 4 Intraparticle diffusion plots at different concentrations: a natural clinoptilolite (NC) and b homoionic clinoptilolite (HC)
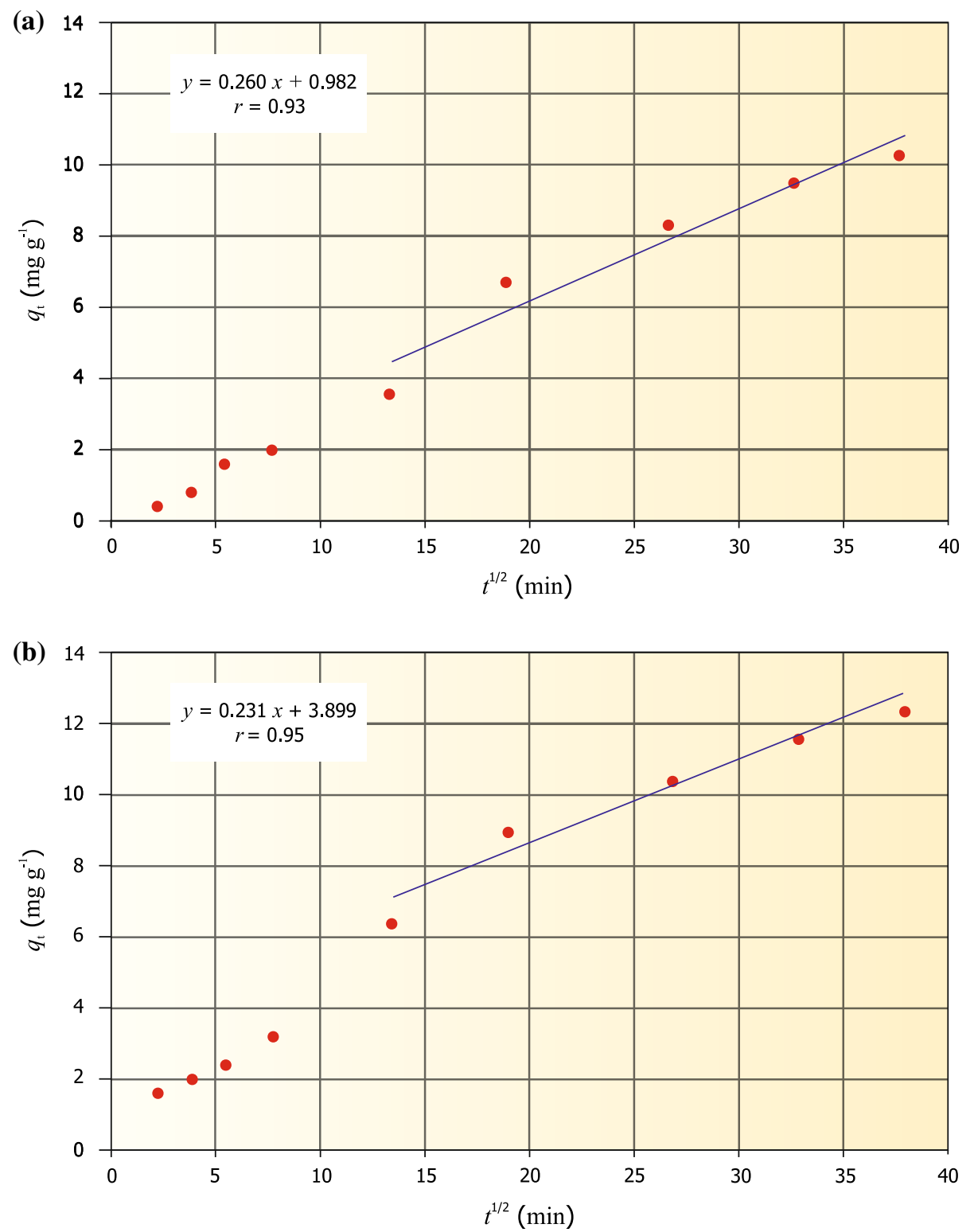

\section{Theoretical modeling of breakthrough curves}

Based on the modeling of the ion exchange process, Fig. 5 outlines the experimental measurements (points), as well as linear and nonlinear curves predicted for hardness sorption by $\mathrm{NC}$ and clinoptilolite pretreated with $\mathrm{NaCl}(\mathrm{HC})$, according to the fitted parameters of the Thomas model presented in Table 3. In this study, the Thomas model was used to fit the column data to obtain the Thomas rate constant $\left(k_{\mathrm{T}}\right)$ and the maximum solid phase concentration $\left(q_{0}\right)$. The values of equilibrium uptake per gram of the adsorbent $\left(q_{\mathrm{e}}, \mathrm{mg} \mathrm{g}^{-1}\right)$ from experimental parameters of breakthrough curves were also listed in Table 2. Taking into consideration the above results, the Thomas model fitted well to the experimental points obtained for the hardness sorption, considering the SHW solution and the packed column reactor under different ion exchange media pretreatment.

From Table 3, it can seen that the values of the NashSutcliffe coefficient (NS) ranged from 0.909 to 0.976 and the root mean square error (RMSE) ranged between 0.050 and 0.097 . In the same way, the mean absolute error $(M A E)$ ranged between 0.042 and 0.077 and the residual bias (BIAS) varied from 0.019 to 0.078 . Hence, the quantitative evaluation between $C_{\mathrm{t}} / C_{0}$ and time as expressed in Eq. 12 was significant, showing that the nonlinear regressive method was more effective in predicting the sorption kinetics than linear method (Table 3). Similar results have been reported by Han et al. (2007) in their comparative analysis for metyhylene blue adsorption onto natural 
Table 2 Summary of the experimental parameters of the ion exchange column packed with natural and homoionic clinoptilolite for water softening

\begin{tabular}{llll}
\hline Parameter $^{\mathrm{a}}$ & Unit & Clinoptilolite \\
\cline { 3 - 4 } & & Natural & Homoionic \\
\hline$C_{0}$ & $\mathrm{mg} \mathrm{L}$ & 240 & 240 \\
$Q_{\mathrm{v}}$ & $\mathrm{ml} \mathrm{min}^{-1}$ & 14.5 & 14.5 \\
$M$ & $\mathrm{~g}$ & 1122.5 & 1122.5 \\
$t_{\mathrm{b}}$ & $\mathrm{min}$ & 12 & 22 \\
$V_{\mathrm{b}}$ & $\mathrm{L}$ & 10 & 18 \\
$t_{\mathrm{s}}$ & $\mathrm{h}$ & 188 & 199 \\
$V_{s}$ & $\mathrm{~L}$ & 160 & 170 \\
$q_{\mathrm{tb}}$ & $\mathrm{mg} \mathrm{g}^{-1}$ & 3.76 & 4.87 \\
$q_{\mathrm{s}}$ & $\mathrm{mg} \mathrm{g}^{-1}$ & 12.0 & 15.4 \\
$H R$ & $\%$ & 33.1 & 42.5 \\
\hline
\end{tabular}

${ }^{a} C_{0}$ initial hardness solution concentration, SHW, $Q_{\mathrm{v}}$ flow rate, $M$ clinoptilolite dry weight, $t_{\mathrm{b}}$ breakthrough time, $V_{\mathrm{b}}$ breaktrough volume, $t_{\mathrm{s}}$ saturation time, $V_{\mathrm{s}}$ saturation volume, $q_{\mathrm{tb}}$ sorption at breakthrough, $q_{\mathrm{s}}$ sorption at saturation, $H R$ hardness removal at saturation

zeolite. Moreover, to provide an additional test of the Thomas model equation, the total sorption capacity $q_{0}$ calculated from Eq. 18 and $q_{\mathrm{e}}$ calculated from the area above the $S$ curves up to the saturation point should be close to each other (Eq. 8). The agreement of $q_{0}$ and $q_{\mathrm{e}}$ (Tables 2,3) confirmed the applicability of the Thomas model to the examined column system.

Although the linear and nonlinear methods are suitable for predicting the dynamic behavior of the column with respect to both natural and homoionic conditions, the results demonstrate that the values of the constant $k_{\mathrm{T}}$ and $q_{0}$ obtained by nonlinear regression are not similarity with the linear transform values. As seen from Table 3 and Fig. 5, the value of equilibrium uptake per gram of adsorbent, $q_{0}$, was higher for linearized model form onto $\mathrm{NC}$ (13.96 $\mathrm{mg} \mathrm{g}^{-1}$ ) and $\mathrm{HC}\left(15.20 \mathrm{mg} \mathrm{g}^{-1}\right)$, as compared to the non-linear form (NC, $11.30 \mathrm{mg} \mathrm{g}^{-1}$ and $\mathrm{HC}$, $14.90 \mathrm{mg} \mathrm{g}^{-1}$ ). Nevertheless, according to the previous section, the statistics indices of agreements from non-linear regressive method were higher than that linear regressive method. This behavior may be explained by the fact that the slope of the breakthrough curve for the linearized method decreased with increasing time as compared to nonlinear method, thereby resulting in a slightly steeper slope for the non-linear method and reducing the adsorption capacity. The steepness of curve is a measure of the efficiency of column to reach saturation (Singh et al. 2012).

In this study, higher sorption capacities are obtained from the column experiments than from the batch tests. From Table 1, sorption capacities obtained from batch tests are roughly 9.68 and $10.50 \mathrm{mg} \mathrm{g}^{-1}$ for $\mathrm{NC}$ and $\mathrm{HC}$ (calculated using the Langmuir equation), respectively. Similar results were reported by Tor et al. (2009), Gupta et al. (2001) and Chen et al. (2011). There may be several reasons for the observed discrepancies between the batch and column systems. One likely reason may be that the NC and the $\mathrm{HC}$ may form aggregates in the columns that favor enhanced solid state diffusion relative to the batch tests (Lopez et al. 1998).

In this context, the results demonstrate that the adsorption bed capacity increase with homoionic pretreatment of clinoptilolite (Table 3). According to Han et al. (2007), this may be associated with an increase the driving force of mass transfer in the liquid film. Furthermore, hardness ions are more strongly bound to clinoptilolite pretreated with $\mathrm{NaCl}$, compared to natural clinoptilolite, as well as to increased distribution coefficients that are indicative for more complete exchange process. In spite of all this, the lower performance onto natural clinoptilolite can be compensated by its low cost so it is still considered as ideal adsorbent to remove hardness ions for water softening applications. Nonetheless, it should be noted, however, that applied results may vary depending on local geochemistry, which essentially suggest the necessity to extent this approach in natural waters. Performance evaluation of ion exchange process using a pilot testing for removal of hardness from groundwater is underway and will be presented elsewhere.

\section{Conclusions}

Removal of hardness ions from aqueous solutions for purified water has been an area of substantial technological interest. Various technologies have been adopted for water softening; however, in most alternatives high power consumption and expenses are required for operation and maintenance of the equipment. In this research, a combined use of batch and column experiments were performed in laboratory conditions through the ion exchange process, evaluating the effectiveness of $\mathrm{NC}$ and sodium $\mathrm{HC}$ on the removal characteristics of divalent cations. All tests were performed with a synthetic hard water (SHW), obtained with the same ionic concentrations of a karst spring. Therefore, on the base of the experimental results of this investigation, the following conclusions can be drawn:

Results of adsorption experiments showed that the hardness ions exhibited high adsorption capacity toward clinoptilolite-rich rocks, a cationic exchange media. The experimental adsorption equilibrium data were best described by the Langmuir isotherm model and the adsorption kinetics can be successfully fitted to pseudosecond-order kinetic model. The results of the intraparticle 
Fig. 5 Breakthrough curves for hardness sorption and ion exchange processes in the packed column: a comparison of experimental points, linear and nonlinear predicted curves of the Thomas model for natural clinoptilolite (NC) and b comparison of experimental points, linear and nonlinear predicted curves of the Thomas model for homoionic clinoptilolite (HC) (a)

HWS volume (L)
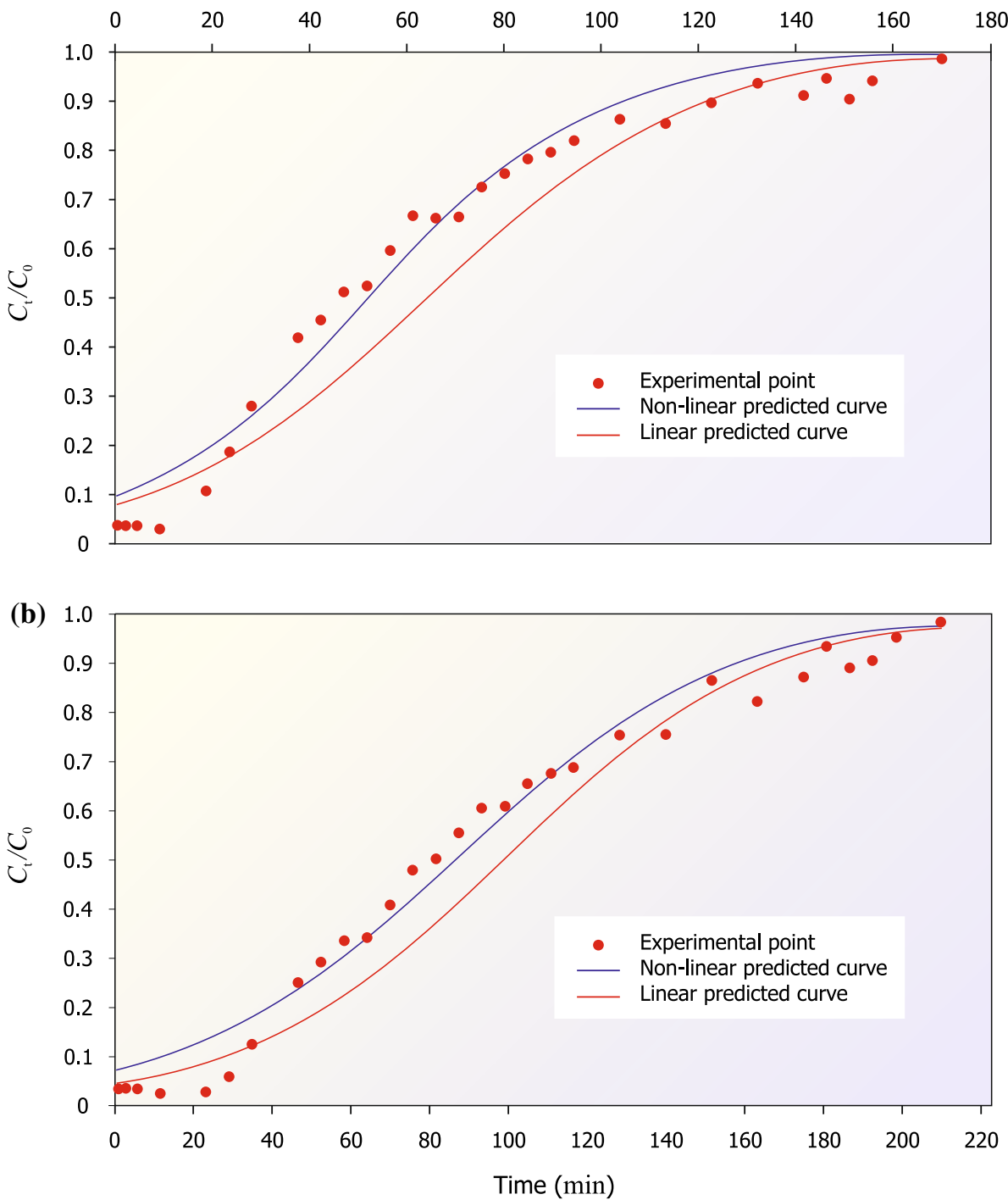

diffusion model suggest intraparticle diffusion was not the only rate-controlling step and indicated some degree of boundary layer control in the process of this sorbate-sorbent system. As a result, batch adsorption experiments have shown that the amount of adsorbed $\left(q_{\mathrm{e}}\right)$ for the Langmuir isotherm indicates a monolayer sorption capacity of clinoptilolite, which indicates a stronger affinity for $\mathrm{HC}$ $\left(10.5 \mathrm{mg} \mathrm{g}^{-1}\right)$ than for the $\mathrm{NC}$ form $\left(9.68 \mathrm{mg} \mathrm{g}^{-1}\right)$. The values obtained are found to agree with the values reported in the literature.

From the perspective of process modeling, the dynamic behavior of a fixed-bed column is described in terms of breakthrough curve. Thus, in the present study, linear and non-linear methods were used to determine the model parameters and a comparative analysis was made between the linear and non-linear method in estimating the relative parameters for the adsorption of water hardness onto clinoptilolite. That is, it was observed that the statistics indices of agreements from non-linear Thomas model were better than that linear Thomas model. Nevertheless, the slope of the breakthrough curve for the linearized method decreased with increasing time as compared to non-linear method, thereby resulting in a slightly steeper slope for the non-linear method and reducing the adsorption capacity. Based on the modeling of the ion exchange process, the study also concludes that the non-linear method is slightly more effective in predicting the performance of the selective removal efficiency of hardness ions.

Natural zeolites have been widely used in water treatment and especially clinoptilolite, due to its low cost and high abundance. It has large cation-exchange capacity and is capable of removing large quantities of hardness ions from water samples. By loading the surface of clinoptilolite a homoionic pretreatment to sodium form, a total 
Table 3 Estimation of parameters for the Thomas model through the ion exchange process in the column test at different experimental conditions

\begin{tabular}{|c|c|c|c|c|c|}
\hline \multirow[t]{3}{*}{ Parameter } & \multirow[t]{3}{*}{ Unit } & \multicolumn{4}{|c|}{ Thomas model } \\
\hline & & \multicolumn{2}{|l|}{ Non-linear } & \multicolumn{2}{|l|}{ Linearized } \\
\hline & & Natural & Homoionic & Natural & Homoionic \\
\hline$a$ & & 0.043 & 0.037 & 0.038 & 0.044 \\
\hline$b$ & & 2.273 & 2.580 & 2.482 & 3.117 \\
\hline$k_{\mathrm{T}}$ & $\mathrm{ml} \mathrm{min}{ }^{-1} \mathrm{mg}^{-1}$ & $2.59 \times 10^{-3}$ & $2.23 \times 10^{-3}$ & $2.29 \times 10^{-3}$ & $2.65 \times 10^{-3}$ \\
\hline$q_{0}$ & $\mathrm{mg} \mathrm{g}^{-1}$ & 11.3 & 14.9 & 13.9 & 15.2 \\
\hline Nash $(N S)$ & $(-)$ & 0.970 & 0.976 & 0.909 & 0.953 \\
\hline$R M S E$ & $(-)$ & 0.056 & 0.050 & 0.097 & 0.071 \\
\hline$M A E$ & $(-)$ & 0.048 & 0.042 & 0.077 & 0.058 \\
\hline BIAS & $(-)$ & 0.029 & 0.019 & 0.078 & 0.045 \\
\hline
\end{tabular}

Nash = coefficient of efficiency. Optimal value $=1.0(-\infty<N S \leq 1.0)$

$R M S E=$ root mean square error. Optimal value $=0.0(0.0 \leq R S M E)$

$M A E=$ mean absolute Error. Optimal value $=0.0(0.0 \leq M A E)$

$B I A S=$ residual BIAS. Optimal value $=0.0(-\infty<B I A S \leq+\infty)$ improvement in adsorption capacity can be achieved. Thus, the homoionic clinoptilolite system is capable of adsorbing slightly more ionic concentrations than natural clinoptilolite with simultaneous noticeable decrease in water hardness. It may be concluded that clinoptilolite may be used as a low cost, natural and abundant source for the removal of the hardness ions and it may be an alternative to more costly materials.

Acknowledgments The authors would like to acknowledge the Ministère des Relations Internationales du Quebec, the Consejo Nacional de Ciencia y Tecnología (CONACyT B330.523), the Universidad Autónoma del Estado de México (UAEM FE052 and FE053), the Institut national de la recherche scientifique INRS-ETE, and the Ministère d'Éducation du Québec for providing funding and logistical support for this study. The authors are also grateful for the technical support of the laboratory technicians from the Interamerican Centre of Water Resources (CIRA) in Toluca Mexico.

\section{References}

Benefield LD, Judkins JF Jr, Weand BL (1982) Process chemistry for water and wastewater treatment. Prentice-Hall, Englewood Cliffs, p 510

Benguella B, Benaissa H (2002) Cadmium removal from aqueous solutions by chitin: kinetic and equilibrium studies. Water Res 36:2463-2474

Bibiano-Cruz L (2009) Inducción del ablandamiento en aguas carbonatadas mediante procesos fisicoquímicos de desgasificación del $\mathrm{CO}_{2}$ y mecanismos de sorción. Universidad Autónoma del Estado de México, Tesis de Doctorado en Ingeniería 215 p

Chen DZ, Zhang JX, Chen JM (2010) Adsorption of methyl tert-butyl ether using granular activated carbon: equilibrium and kinetic analysis. Int J Environ Sci Tech 7(2):235-242

Chen N, Zhang Z, Feng C, Li M, Chen R, Sugiura N (2011) Investigations on the batch and fixed-bed column performance of fluoride adsorption. Desalination 268:76-82
Chiavola A, D'Amato E, Baciocchi R (2012) Ion exchange treatment of groundwater contaminated by Arsenic in the Presence of Sulphate: breakthrough Experiments and Modeling. Water Air Soil Pollut 223:2373-2386

Cinar S, Beler-Baykal B (2005) Ion exchange with natural zeolites: an alternative for water softening? Water Sci Technol 51:71-77

Cuda P, Pospisil P, Tenglerova J (2006) Reverse osmosis in water treatment for boilers. Desalination 198:41-46

Dişli E (2010) Batch and column experiments to support heavy metals $(\mathrm{Cu}, \mathrm{Zn}$, and $\mathrm{Mn})$ transport modeling in alluvial sediments between the Mogan Lake and the Emir Lake, Gölbaşi Ankara. Ground Water Monit Remediat 30(3):125-139

Eckenfelder WW (2000) Industrial water pollution control. McGrawHill Series in Water Resources and Environmental Engineering 3rd edn McGraw-Hill Higher Education, p 584

Fu Y, Viraraghavan T (2003) Column studies for biosorption of dyes from aqueous solutions on immobilized Aspergillus niger fungal biomass. Water SA 29(4):465-472

Gabrielli C, Maurin G, Francy-Chausson H, Thery P, Tran TTM, Tlili M (2006) Electrochemical water softening: principle and application. Desalination 201:150-163

Ghizellaoui S, Chibani A, Ghizellaoui S (2005) Use of nanofiltration for partial softening of very hard water. Desalination 179:315-322

Gorimbo J, Taenzana B, Kapanji K, Jewell LL (2014) Equilibrium ion exchange studies of $\mathrm{Ni}^{2+}$ on homoionic forms of clinoptilolite. S Afr J Sci 110(5/6):1-7. doi:10.1590/sajs.2014/20120027

Gupta V, Gupta M, Sharma S (2001) Process development for the removal of lead and chromium from aqueous solutions using red mud, an aluminium industry waste. Water Res 35:1125-1134

Han R, Wang Y, Zou W, Wang Y, Shi J (2007) Comparison of linear and nonlinear analysis in estimating the Thomas model parameters for methylene blue adsorption onto natural zeolite in fixedbed column. J Hazard Mater 145:331-335

Helferrich F (1962) Ion exchange. McGraw-Hill, New York, p 154

Ho YS, McKay G (1999) Pseudo-second order model for sorption processes. Process Biochem 34:451-465

Ho YS, Ng JC, McKay G (2000) Kinetics of pollutant sorption by biosorbents: review. Sep Purif Methods 29(2):189-232

Korngold E, Belayev N, Aronov L (2001) Removal of arsenic from drinking water by anion exchangers. Desalination 141:81-84 
Kumar PA, Ray M, Chakraborty S (2009) Adsorption behavior of trivalent chromium on amine-based polymer aniline formaldehyde condensate. Chem Eng J 149:340-347

Liu H, Dong Y, Wang H, Liu Y (2010) Adsorption behavior of ammonium by a bioadsorbent-Boston ivy leaf powder. J Environ Sci 22(10): 1513-1518

Lopez E, Soto B, Arias M, Nunez A, Rubinos D, Barral MT (1998) Adsorbent properties of red mud and its use for wastewater treatment. Water Res 32:1314-1322

Meshko V, Markovska L, Mincheva M, Rodrigues E (2001) Adsorption of basic dyes on granular activated carbon and natural zeolite. Water Res 35:3357-3366

Mittal A, Kurup L, Mittal J (2007) Freundlich and Langmuir adsorption isotherms and kinetics for the removal of Tartrazine from aqueous solutions using hen feathers. J Hazard Mater 146(1-2):243-248

Mohan D, Pittman CU Jr (2007) Arsenic removal from water/ wastewater using adsorbents-a critical review. J Hazard Mater 142:1-53

Özcan AS, Özcan A (2004) Adsorption of acid dyes from aqueous solutions onto acid-activated bentonite. J Colloid Interface Sci 276:39-46

Park JS, Song JH, Yeon KH, Moon SH (2007) Removal of hardness ions from tap water using electromembrane processes. Desalination 202:1-8

Rabideau AJ, Van Benschoten J, Patel A, Bandilla K (2005) Performance assessment of a zeolite treatment wall for removing Sr-90 from groundwater. J Contam Hydrol 79:1-24

Reynolds TM, Richards PA (1996) Unit operations and processes in environmental engineering. PWS Publishing Co., Boston, p 364
Rivas FJ, Beltrán FJ, Gimeno O, Frades J, Carvalho F (2006) Adsorption of landfill leachates onto activated carbon. Equilibrium and kinetics. J Hazard Mater B131:170-178

Singh A, Kumar D, Gaur JP (2012) Continuous metal removal from solution and industrial effluents using Spirogyra biomass-packed column reactor. Water Res 46:779-788

Smith EJ, Davison W, Taylor H (2002) Methods for preparing synthetic freshwaters. Water Res 36:1286-1296

Stumm W, Morgan JJ (1996) Aquatic chemistry: chemical equilibria and rates in natural waters. Wiley, New York, p 1040

Tor A, Danaoglu N, Arslan G, Cengeloglu Y (2009) Removal of fluoride from water by using granular red mud: batch and column studies. J Hazard Mater 164:271-278

Weber WJ Jr, Morris JC (1964) Equilibria and capacities for adsorption on carbon. J Sanit Eng Div 90(3):79-108

Williams DJ, Benjamin EH, Angus P, Wilkinson AP (2002) First-year undergraduate laboratory experiments with zeolites. Chem Educ $7(1): 33-36$

Yildiz E, Nuhoglu A, Keskinler B, Akay G, Farizoglu B (2003) Water softening in a crossflow membrane reactor. Desalination, Vol. 159-Issue 2, pp 139-152

Zhou D, Zhang L, Zhou J, Guo S (2004) Development of a fixed-bed column with cellulose/chitin beads to remove heavy-metal ions. J Appl Polym Sci 94:684-691

Zou W, Bai H, Zhao L, Li K, Han R (2011) Characterization and properties of zeolite as absorbent for removal of uranium(VI) from solution in fixed bed column. J Radioanal Nucl Chem 288:779-788 